\title{
Instituições e prosperidade
}

\author{
Institutions and prosperity
}

Maurício Michel Rebello ${ }^{1}$

Matheus Gomes Pereira²

\begin{abstract}
Resumo: através de uma pesquisa colaborativa que durou cerca de quinze anos, Daron Acemoglu e James Robinson em Why Nations Fail, publicado no ano de 2012, estabelecem um novo olhar para o sucesso e o fracasso das nações. Em seu trabalho, Acemoglu e Robinson discutem a importância das instituições para o desenvolvimento e respondem, de modo ousado, as diferenças de riqueza entre os países. Para realizar essa atividade, os autores se fazem valer de um método qualitativo, retomando acontecimentos históricos de diversas nações e reinterpretando-os sob a luz de uma nova teoria. Por consequência, sua obra realiza uma análise do desenvolvimento dos países e suas instituições a partir de um path dependence.
\end{abstract}

Palavras-chave: Teoria, Desenvolvimento, Instituições.

\begin{abstract}
Daron Acemoglu and James Robinson in Why Nations Fail, published in the year 2012, establish a new analysis at the success and failure of nations. In his work, Acemoglu and Robinson contend the importance of institutions for the development and respond to the differences in wealth between the countries. To accomplish this activity, the authors work with a qualitative method, retaking historical events from various nations and reinterpreting the events under a new theory. Consequently, its work carries out an analysis of the development of the countries and their institutions from a path dependence
\end{abstract}

Keywords: Theory; Development; Institutions.

Investigar os fatores que determinam o desenvolvimento econômico é uma tarefa substancial para a compreensão das diferenças de renda entre as nações. Tal ofício requer um entendimento dos motivos que constituem a prosperidade de um Estado. Na preposição de Adam Smith (1776), a prosperidade de uma nação deriva de sua capacidade produtiva. Em vista disso, se a riqueza e a prosperidade de um Estado se traduzem pela sua produtividade, qual é o elemento que consagra a diferença de produção entre as nações e, consequentemente, gera as desigualdades entre si?

Diferentemente de Montesquieu e Jared Diamond que vislumbravam a diferença de prosperidade entre nações a partir do seu aspecto geográfico, para Daron Acemoglu e James Robinson (2012), a resposta para o entendimento da desigualdade entre os países se encontra nas suas respectivas instituições políticas e econômicas. Nesse sentido, Acemoglu e Robinson em "Por Que as Nações Fracassam" apresentam uma explicação baseada a partir de path dependece para entender os mo- 
tivos que levam algumas nações prosperar e outras não. De caráter meramente especulativo, tal interpretação consiste na discrepância das instituições entre as nações, persistindo na existência de instituições políticas e econômicas inclusivas e extrativistas.

Seguindo a lógica de Acemoglu e Robinson, podemos entender as instituições políticas inclusivas como promotoras da prosperidade, assegurando a centralização política e pluralidade, bem como o direito de propriedade aos indivíduos e a manifestação de diferentes atores políticos. É perante instituições políticas inclusivas que instituições econômicas inclusivas florescem em uma nação.

De modo antagônico, instituições extrativistas se destacam pelo seu caráter elitista, onde seu sistema político e econômico se restringe a apenas um determinado grupo do tecido social, trabalhando somente em favor de seu próprio benefício. Em contexto de instituições extrativistas, os ganhos econômicos da nação se destinam apenas para a elite privilegiada, assim como inibe qualquer possibilidade atuação livre dos indivíduos na economia, acarretando na ausência de inovação econômica. Não obstante, para Acemoglu e Robinson há possibilidades de haver crescimento econômico sob o seio de instituições extrativistas, entretanto, os autores afirmam que o desenvolvimento não se manterá a longo prazo, sendo apenas possível um crescimento sustentável em instituições inclusivas.

O crescimento sustentável de instituições inclusivas se dá pelo fato de que economias inclusivas incentivam a inovação engendrada pela destruição criativa. Tal aspecto não ocorre em instituições extrativistas, pois conforme apresentado pelos autores, as elites temem a inovação econômica pelos riscos que esta pode apresentar na consolidação do poder das mesmas.

No âmbito da economia, o conceito de destruição criativa formulado por Schumpeter (1982) se designa ao processo de inovação no mercado. Em outras palavras, é o processo de destruição do modelo produtivo arcaico por novos modelos de negócio. Municiado desse conceito de Schumpeter para denominar o crescimento econômico e as mudanças tecnológicas, Acemoglu e Robinson encaram a destruição criativa como o alicerce das instituições inclusivas, gerando embates no campo político e no mercado econômico. "É o temor da destruição criativa que, em geral, se encontra na origem da oposição às instituições políticas e econômicas inclusivas" (ACEMOGLU \& ROBINSON, 2012: 66)

Com a finalidade de esclarecer a prática da destruição criativa e o exercício das instituições inclusivas na história britânica, Acemoglu e Robinson se utilizam do percurso europeu às vésperas da Revolução Industrial para explicá-las.

[...] no século XVIII, os governos da maioria dos países europeus eram controlados por aristocracias e elites tradicionais, cujas principais fontes de renda eram a propriedade da terra ou os privilégios comerciais de que usufruíam graças aos monopólios conferidos e barreiras alfandegárias impostas pelos monarcas. De acordo com a ideia de destruição criativa, a disseminação das indústrias, fábricas e cidades retirou recursos da terra, reduziu o valor dos aluguéis das propriedades e aumentou os salários que os proprietários rurais tinham de pagar aos seus funcionários. Essas elites também assistiram ao surgimento de novos empresários e mercadores, que erodiu seus privilégios comerciais. De modo geral, foram claramente eles que, em termos econômicos, saíram perdendo com a industrialização. A urbanização e a emergência de uma classe média e operária mais consciente em termos sociais também vieram desafiar o monopólio político das aristocracias rurais, de modo 
que a difusão da Revolução Industrial não Ihes traria a derrota apenas no âmbito econômico; corriam o risco também de perderem seu domínio no campo político. Com seu poderio político e econômico em xeque, essas elites tendiam a oferecer uma formidável oposição à industrialização (ACEMOGLU \& ROBINSON, 2012: 66- 67).

Se de um lado temos a interpretação de Acemoglu e Robinson com a benéfica destruição criativa ocasionada pela Revolução Industrial, de outro temos Karl Polanyi (1944) e seu moinho satânico que se assegurou de destruir o tecido social sob a luz do mesmo período. Polanyi, em suas análises, alega a falha do liberalismo econômico ao interpretar a história da Revolução Industrial, tendo em vista a insistência em avaliar os acontecimentos sociais a partir de um ponto de vista meramente econômico.

Para ilustrar tal fato, Polanyi retoma o cercamento dos campos e a conversão da terra arável em pastagens de carneiros.

Os cercamentos foram chamados, de uma forma adequada, de revolução dos ricos contra os pobres. Os senhores e os nobres estavam perturbando a ordem social, destruindo as leis e os costumes tradicionais, às vezes pela violência, às vezes por pressão e intimidação. Eles literalmente roubavam o pobre na sua parcela de terras comuns, demolindo casas que até então, por força de antigos costumes, os pobres consideravam como suas e de seus herdeiros. O tecido social estava sendo destruído; aldeias abandonadas e ruínas de moradias humanas testemunhavam a ferocidade da revolução, ameaçando as defesas do país, depredando suas cidades, dizimando sua população, transformando seu solo sobrecarregado em poeira, atormentando seu povo e transformando-o de homens e mulheres decentes numa malta de mendigos e ladrões. [...] No que se refere à Inglaterra, é certo que o desenvolvimento da indústria lanígera foi um recurso para o país levando, como o fez, ao estabelecimento da indústria têxtil - o veículo da Revolução Industrial. Além disso, é claro também que o incremento da tecelagem doméstica dependia do aumento do fornecimento doméstico de lã. Esses fatos são suficientes para identificar a mudança da terra arável para a pastagem e o movimento de cercamentos que a acompanhou como a tendência do progresso econômico (POLANYI, 1944: 53-55)

Na perspectiva de Polanyi, o exercício da autorregulação do livre mercado por si só implica em ignorar as limitações que o desenvolvimento pode ocasionar. No entanto, isto não sugere que Polanyi iria de encontro à ideia de destruição criativa. Pelo contrário, a transformação de um modelo econômico para outro de modo tão abrupto é que não deveria ser entendida como desenvolvimento e crescimento contínuo.

Obviamente podemos alegar que o caso da Revolução Industrial em Acemoglu e Robinson pode, em última instância, se tornar a exceção da regra. Entretanto, para afirmar com precisão se determinadas instituições estão sendo de fato extrativistas ou apenas resguardando sua população de um moinho satânico, faz-se necessário esmiuçar um estudo de toda abordagem realizada por Acemoglu e Robinson.

Tratando-se de um livro que propõe uma teoria de largo alcance, o que, em termos de ciências sociais, é elogiável por si só, algumas limitações do livro são explícitas. 1) Há falta de precisão conceitual no uso de alguns indicadores. Há uma confusão conceitual entre riqueza, Produto Interno 
Bruto, Renda e Poder de Paridade de Compra. Esta falha vai ser importante, uma vez que os autores se propõem a comparar o quanto uma nação é mais "próspera" que a outra. 2) O conceito de prosperidade não é definido de maneira precisa. O livro deixa a entender que o conceito se refere somente à PIB per capita e riqueza, algo, por si só, muito duvidoso, tendo em vista outros indicadores como a felicidade interna bruta e o índice de desenvolvimento humano.

Não obstante, das fragilidades que constituem as argumentações de Acemoglu e Robinson, destaca-se sua clara visão liberal na interpretação do capitalismo. Os autores afirmam que instituições extrativas dificultam a inovação e a prosperidade em longo prazo. Como, então, interpretar a extração da mais-valia dentro do capitalismo? Não seria ela uma forma extrativista? Em determinado momento do livro (p. 251), os autores chegam próximo a este ponto ao relatar os trustes norte-americanos no início do século XX. Contudo, relatam que isto foi resolvido com as leis antitrustes. Ora, em um capitalismo no qual algumas poucas empresas multinacionais controlam um vasto mercado e onde o acúmulo de riqueza do centésimo mais rico da população ultrapassa $30 \%$ em alguns países (Piketty, 2014), como podemos falar de instituições inclusivas?

Em síntese, a tese proposta por Acemoglu e Robinson tem sua relevância por ser uma explicação de longo alcance. Além disso, o livro resgata diferentes histórias de diversas sociedades ao longo da civilização. A interpretação forte de path dependence do institucionalismo histórico faz com que "um bater de asas" no século XV tenha repercussões nos acontecimentos do século XXI. Ainda assim, negam tautologias, mostrando como o desenvolvimento inclusivo ou extrativo pode ter seu percurso alterado por eventos dramáticos. Enfim, a obra oferece um grande debate do futuro das nações.

\section{Referências}

PIKETTY, Thomas. O capital no século XXI. Rio de Janeiro: Intrínseca, 2014.

POLANYI, Karl. A grande transformação: as origens da nossa época. Rio de Janeiro: Campus, 2000. SCHUMPETER, J. Socialismo, capitalismo e democracia. Rio de Janeiro: Zahar, 1982.

SMITH, Adam. Riqueza das nações. São Paulo: Nova Cultura, 1996.

Recebido: 07/05/2019

Aceito: $12 / 06 / 2018$

Publicado: 28/09/2018 


\section{Biografia do autor}

\section{Maurício Michel Rebello}

Doutor em Ciência Política pela Universidade Federal do Rio Grande do Sul (UFRGS). Professor adjunto do curso de Licenciatura em Ciências Sociais da Universidade Federal da Fronteira Sul (Campus Erechim). ORCID: https://orcid.org/o000-0003-3607-969X; E-mail: mmrebello@yahoo.com.br

\section{Matheus Gomes Pereira}

Aluno de graduação em Licenciatura em Ciências Sociais da Universidade Federal da Fronteira Sul (UFFS) - Campus Erechim. ORCID: https://orcid.org/0000-0002-9202-8072; E-mail:mg_96@gmail.com Instituição: Universidade Federal da Fronteira Sul (UFFS);

Localização: Av. Fernando Machado, 108E - Centro, Chapecó - SC, 89814-470 